\title{
Heterogeneity of sport event volunteer motivations: A segmentation approach
}

\author{
EUNJUNG KIM, LIZ FREDLINE AND GRAHAM CUSKELLY \\ Department of Tourism, Sport and Hotel Management, Griffith Business School, \\ Griffith University, Gold Coast Campus, Southport, Queensland, Australia
}

\begin{abstract}
This study identifies specific sport event volunteer motivations, and then segments sport event volunteers based on their motivations. It investigates the distinct features of four motivational clusters in terms of their socio-demographics, their volunteering-related experiences, and the type of sport event at which they volunteered. The data comprises a sample of 337 volunteers from three sport events in Queensland. The Volunteer Motivation Scale for International Sporting Events (VMS-ISE) questionnaire is used and data are analyzed using exploratory factor analysis and hierarchical cluster analysis on standardized variables. Chisquare tests are then undertaken to explore relationships with other variables. The results indicate that motivations differ among the four main groups identified. Event organizers will be able to use this understanding of differing motivations to develop more effective volunteer management strategies.
\end{abstract}

Key words: Cluster analysis, sport event, volunteer, motivation 


\section{Introduction}

Volunteering is an important part of the tourism and leisure sectors and can take a variety of forms. Volunteer tourism, which involves people travelling to participate in volunteering activities, often in developing countries, is an important and growing trend (Guttentag, 2009) which is attracting more research attention (Elliott, 2008). About 1.6 million people worldwide join volunteer tourism projects annually and these volunteer tourists spend between $£ 832$ million and $£ 1.3$ billion per year (equivalent to AUD 1.5 billion-2.3 billion) (Tourism Research \& Marketing, 2008).

A more established trend in volunteering is locals who volunteer at attractions and events that help bring tourists to a destination. These volunteers provide important human resources to tourism and event organisations and are therefore an important component of the tourism industry. As mainstream tourism researchers have argued for the need to better manage tourismrelated business (Barbieri, Santos, \& Katsube, 2012; Benson \& Henderson, 2011; Tribe, 2008), effective volunteer management is an important dimension that needs to be informed by research.

Recruitment of volunteers is a significant part of the human resource management processes and critical to hosting many successful sport events (Sharififar, Ganjouie, Tondnevis, \& Zarei, 2011). The International Labor Organization (2011) argued that volunteer work is most effective when properly managed. Event organizers rely on the assistance of volunteers, often in large numbers, in the lead up to and particularly during the staging of events. Therefore, it is important to build a mutual relationship between volunteers and event organizers to promote strong volunteer engagement. Such a close and well-established relationship between volunteers and event organizers would be expected to make a meaningful contribution to the event and influence volunteers to be more involved in volunteering The quality of the relationship can be influenced by how well volunteer management processes are implemented at a sport event (Taylor, Darcy, Hoye, \& Cuskelly, 2006). 
Volunteers, however, are a highly diverse group and frequently represent different nationalities and cultures, gender, age, career backgrounds, personal characteristics and previous volunteer experiences. Such diverse backgrounds and characteristics are likely to affect motives, needs, desires, and behavior of volunteers (Alexander, Kim \& Kim, 2015). An understanding of the motives and characteristics of individual volunteers or groups of volunteers would best inform decisions about the most appropriate approaches and strategies regarding volunteer management. By segmenting volunteers, sport event organizers might gain a better understanding of the range of factors that influence sport event volunteering and be able to use these factors to recruit, support, and manage volunteers more effectively (Alexander et al. 2015; Schlesinger \& Gubler, 2016).

Although a substantial number of relevant studies have investigated sport event volunteerism with regard to characteristics of volunteers and volunteer management (e.g. Bang, Alexandris, \& Ross, 2008; Bang \& Ross, 2009; Bang, Won, \& Kim, 2009; Dickson, Benson, Blackman, \& Terwiel, 2013; Dickson, Benson, \& Terwiel, 2014; Dickson, Darcy, Edwards, \& Terwiel, 2015, Hallmann \& Harms, 2012; Khoo \& Engelhorn, 2007, 2011; VanSickle, Pierce, \& Diacin, 2015), there are few studies of volunteer segmentation, even though many researchers recognize that volunteers are heterogeneous (Schlesinger \& Gubler, 2016). This research has attempted to address the problem of heterogeneity amongst volunteers using a segmentation approach. Because motivation is one of the main concepts applied to understanding the decisions of individuals to become involved in volunteer activities, an understanding of different profiles of sport event volunteers' motives would help event managers design more advanced and effective volunteer management strategies tailored to the different needs within the volunteer group. Thus, the purpose of this study is to profile and segment sport event volunteers based on their motivation. Further, this research investigates the distinctive features of sport event volunteer clusters based on socio-demographic and volunteer-related experiences across three different sport events. 


\section{Literature review}

Given the substantial contribution of volunteers to events generally and sport events in particular, it is important to try to ensure the sustainability of this valuable resource. Volunteers are more likely to continue to engage with events if they are satisfied with their experiences, and they are more likely to be satisfied if their needs are met. For this reason, it is important to understand motivations for volunteering and the needs that volunteers are seeking to fulfill through their participation in an event. This literature review identifies appropriate theoretical bases for this study and summarizes the previous research which has segmented sport event volunteers on the basis of their motivations. It also describes the range of existing volunteer motivation scales in an effort to inform the design of the study.

\subsection{Theoretical background}

"Theory, or a statement of constructs and their relationships to one another that explain how, when, why, and under what conditions phenomena take place, is a critical element in the advancement of an academic discipline" (Cunningham, 2013, p. 1). Researchers apply theory to develop research questions, determine methods, analyze data, discuss results, and draw conclusions (Sutton \& Staw, 1995). Several theoretical frameworks provide unique ways of approaching critical topics in the field with regard to the motivations of sport event volunteers.

Clary et al. (1998) used functional theory to hypothesize six functions (i.e. values, understanding, social, career, protective motives, and enhancement) potentially served by all kinds of volunteerism and they designed an instrument known as the Volunteer Functions Inventory (VFI) to measure these functions. This functional approach proposed that people involved in similar acts may have different underlying motivations with respect to different functions for doing so. Clary et al. (1998) found that volunteers who were driven by their personally desired functions tended to be more satisfied with their volunteer work and had stronger intentions to continue volunteering. Their investigations provided empirical support for a functional approach focusing on the psychological purposes served by doing volunteer 
activities and highlighted the active role of individuals that reflect important features of self and identity to match the person and the situation.

The Special Event Volunteer Motivation Scale (SEVMS) developed by Farrell, Johnston and Twynam (1998) and Motivation To Volunteer (MTV) for Special Events identified by Monga (2006) are based on the incentives approach of Knoke and Prensky (1984). Knoke and Prensky (1984) identified three underlying volunteer motives which they labeled: normative incentives (referred to as purposive incentives, which are genuine concern for others and a desire to help); affective incentives (referred to as solidary incentives, which are social benefits derived from relationships with a group); and utilitarian incentives (referred to as material incentives, which are benefits from volunteering-such as gaining work experience, skills and tangible benefits). These incentives seem to lie at the core of the mechanisms for volunteering by which individuals exchange valued incentives for engaging in volunteer activities. These three dimensions appeared to be useful in exploring the motivations of volunteers for sport events (Farrell et al., 1998). Farrell et al. (1998) reasoned that volunteer satisfaction with overall experiences is not only a function of fulfilling their expectations, but is also associated with their satisfaction with the facilities and the organization of the event. The incentives approach of Knoke and Prensky (1984) has been applied in several sport event volunteer studies (e.g. Dickson et al., 2013; Dickson et al., 2014; Khoo \& Engelhorn, 2011; Twynam, Farrell, \& Johnston, 2002). Using Principal Components Analysis (PCA), Dickson et al. (2013) and Dickson et al. (2014) found six factors that influence sport event volunteering from 36 motivation items, with the most important factors entitled 'all about the games' and 'altruistic'. Khoo and Engelhorn (2011) identified a five-factor model with the altruistic factor (purposive incentives) being the most important. Twynam et al. (2002) found that special event volunteers indicated motivations across four factors with purposive, commitment, and solidary being stronger motivations than external traditions. Monga (2006) recognized the unique characteristics of special events and highlighted a five-dimensional framework including two additional explanatory dimensions such as affiliatory and egoistic motivations. 
Giannoulakis, Wang, and Gray (2007) argued that studies of volunteerism in non-sport sectors have been unable to identify aspects of volunteering that are unique to sport volunteerism. They suggested that additional research should be conducted in order to establish a conceptualized theory that would identify the significance of motives to volunteer in sport settings. Strigas and Jackson (2003, p. 121) argued that theory “...needs to take under consideration the size, location, purpose, composition of the volunteer labor, and impact of the sport event on the hosting community, and create a taxonomy of sport events for volunteers based on the presiding factors". Based on this theoretical approach, Giannoulakis et al. (2007) developed an instrument known as the Olympic Volunteer Motivation Scale (OVMS) to particularly examine volunteer motivation in the context of the Olympic Games.

The Volunteer Motivation Scale for International Sporting Events (VMS-ISE) by Bang and Ross (2009) suggested that 'love of a sport' appeared to be a unique motivator of sport event volunteers. This concept is related to 'mere love of sport' as an incentive for volunteer activity. The notion of 'love of sport' was drawn from sport fan involvement research grounded in social identity theory (e.g. Jenkins, 1996; Laverie \& Arnett, 2000; MacClancy, 1996). Based on a sport fan involvement approach, the love of sport dimension was conceptualized such that individuals may want to volunteer for sport events because they enjoy sports and love being engaged in activities associated with sport. Also, individuals may have an intention to volunteer at sport events as they have positive feelings and passion for a specific sport (Bang et al., 2008). In this sense, the VMS-ISE added attractiveness of sport as one of sports volunteers' strong motives. Adaptations of the VMS-ISE have been used in several empirical studies (e.g. Bang et al., 2008; Bang \& Ross, 2009; Bang et al., 2009; Hallmann \& Harms, 2012; Schlesinger \& Gubler, 2016; VanSickle et al., 2015).

The incentives approach of Knoke and Prensky (1984) is likely to help identify general incentives aspects of volunteer motivation that can be applied not only to volunteer activities generally, but also to sport event volunteering. In addition, aspects of sport-specific incentives such as 'love of sport' or 'community involvement', may contribute to predicting intention to 
volunteer in sport events (Bang \& Ross, 2009). This study is based on these underlying theoretical foundations.

\subsection{Volunteer motivation scale}

Motivations could be formed by attitudes, beliefs, values and personality which encourage individuals to engage in activities (Chelladurai, 2006), in the case of this research, volunteering. Motivation is highly complex, and can vary, depending on types of events and organizations (Bang \& Ross, 2009). The motivation of sport event volunteers could therefore be considered somewhat differently. There are several research studies related to volunteer motivation scales such as VFI (Clary et al., 1998), SEVMS (Farrell et al., 1998), MTV for Special Events (Monga, 2006), OVMS (Giannoulakis et al., 2007), and VMS-ISE (Bang \& Ross, 2009).

The volunteer motivation scales identified above include sub-scales, which this study has categorized as either common constructs (measured in five scales), shared constructs (measured in two or more scales) or unique constructs (measured on only one of the scales) (see Table 1).

Table 1: Constructs measured by volunteer motivation scales

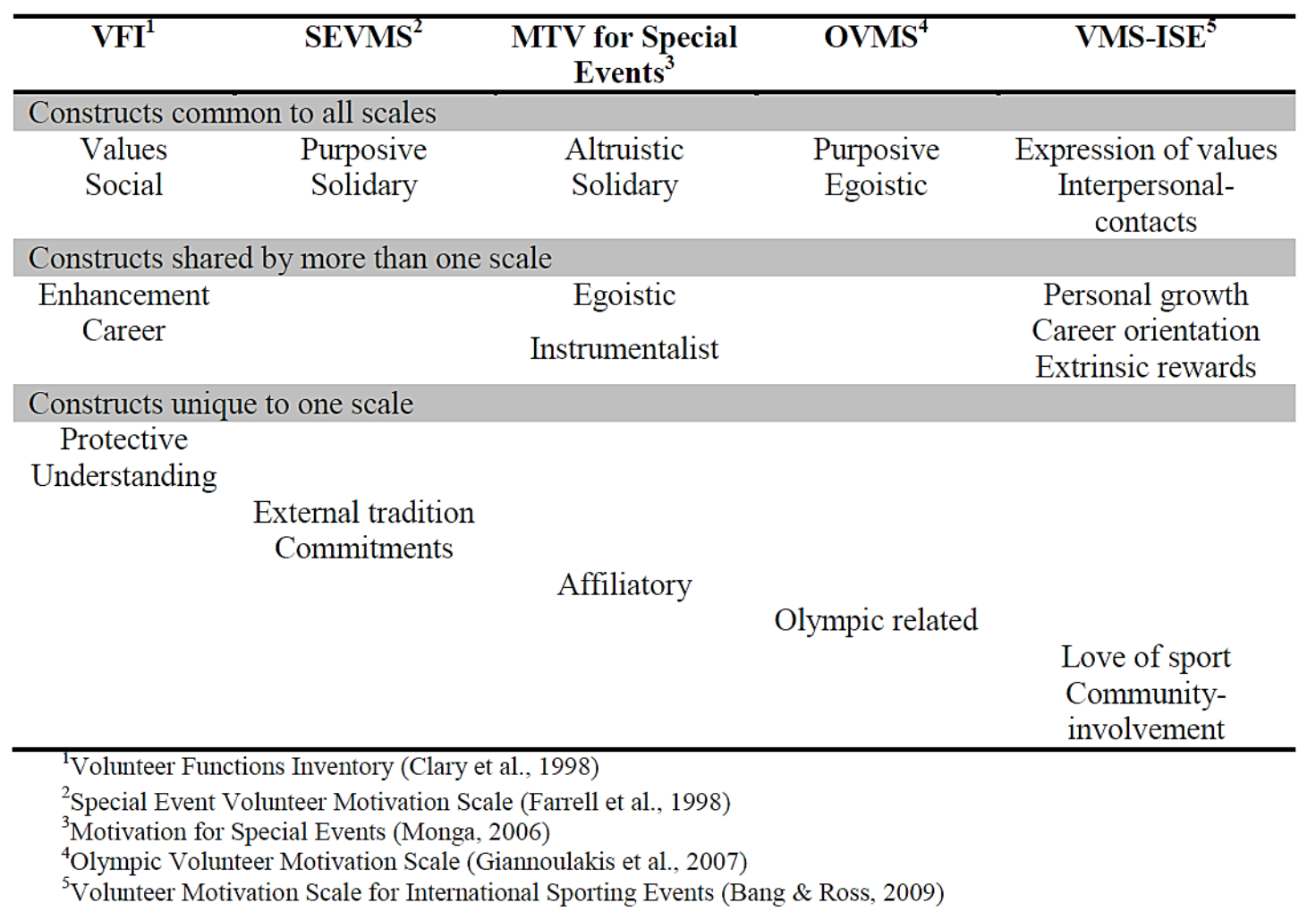


Comparison of these scales shows that altruistic values for other people (that is, values and purposive) and establishing social relationships (that is, social, solidary, and interpersonal contacts) are common motivation factors as they were measured by five of the volunteer motivation scales found in the literature (VFI, SEVMS, MTV for Special Events, OVMS, and VMS-ISE). Growth and development (i.e. enhancement, egoistic, and personal growth), careerrelated benefits and experiences (i.e. career, instrumentalist, and career orientation), and tangible benefits (i.e. instrumentalist and extrinsic rewards) were categorized as shared motivation factors (i.e. evident in the VFI, MTV for Special Events, and VMS-ISE but not in other scales). Unique constructs, as indicated below, were evident in only one of each of the four motivation scales, perhaps as a consequence of the context in which volunteer motivations were measured. 'Protective motives', which is related to reducing one's guilt and addressing one's personal problems and 'understanding', which is concerned with learning and exercising one's skills and knowledge, were each measured only on the VFI. 'External tradition', which is related to family traditions and external influences on an individual's volunteer career, and 'commitments', which is linked to external expectations and personal skills with commitment to volunteering, were found only on the SEVMS. 'Affiliatory motives', which may be in the form of a particular interest to the special event activity, was measured only on the MTV for Special Events. 'Olympic related', which is associated with the Olympic movement and meeting with Olympic athletes, was a factor on the OVMS, which was particularly oriented towards Olympic volunteers. 'Community involvement' (i.e. feeling a sense of belonging, pride, and community spirit) and 'love of sport' (i.e. loving the sport and liking any event of the sport), were measured only on the VMS-ISE. Such unique motivation factors were shown by each scale to be valid and reliable and an appropriate measure of volunteers' motives in the various cases studied.

While the VFI (Clary et al., 1998) and the SEVMS (Farrell et al., 1998) have increased an understanding of volunteer motivation more generally and have been used more widely than other scales, in this case, it is necessary to gain an understanding of the motives of volunteers in the context of various sport events. As the 'love of sport' dimension is integrated into the VMS- 
ISE and the scheme by Bang and Ross (2009), it is likely to be applicable to different type of sport events, so this study is based on the scale developed by Bang and Ross (2009).

\subsection{Segmentation research of the motives of sport event volunteers}

Despite a number of studies on the motivation of sport event volunteers, few previous studies have attempted to segment sport event volunteers according to their motivation. Segmentation research would seem to be an important issue given that volunteers are heterogeneous. It appears as though only two studies have attempted to segment sport event volunteers.

Alexander et al. (2015) used seven motivational factors in a segmentation study of volunteers at the 2012 London Olympic Games. They identified three distinct segments (i.e. obligated, enthusiastic, and semi-enthusiastic) in measuring volunteer satisfaction, behavioral intentions for other future events, and socio-demographic backgrounds. Their study was the first research that developed motivation-based segmentation related to sport event volunteers at a major sport event. By identifying meaningful segments of volunteers, their study focused attention on the strategic importance of understanding the diversity of groupings among sport event volunteers for a targeted-communication approach. However, their study did not appear to be underpinned by an appropriate theoretical framework explaining why these different clusters are represented (Schlesinger \& Gubler, 2016). Further, the Alexander et al. (2015) segmented volunteers at only one major sport event, which limits the generalizability of the results.

For the 2014 European Athletics Championships, Schlesinger and Gubler (2016) investigated the segmentation of sport event volunteers based on their different motivations. Their study used the VMS-ISE and identified four motivation-based volunteer groups (i.e. community supporters, material incentive seekers, social networkers, and career and personal growth orienteers). The groups differed in relation to socio-economic, sport-related and volunteer activity-related variables. Results showed that motivational profiles differed between groups of sport event volunteers, and that volunteers occasionally combine different bundles of motives. Their findings contributed to a better understanding of the heterogeneity of sport event 
volunteers. Although their research had a large sample $(n=1,169)$, Schlesinger and Gubler (2016) evaluated volunteer motives in only one event.

Both the Alexander et al. (2015) and the Schlesinger and Gubler (2016) studies are valuable to the extent that they researched the heterogeneity of event volunteers' motives and identified meaningful event volunteer segments. However, as one-sample studies which have not been repeated within the same event or across different events, the extent to which the event volunteer segments are generalizable to the wider event industry, is limited. Single sample studies, even with large numbers of respondents, leave open the question of findings being replicable.

The current study aims to address these limitations by collecting a sample from volunteers at three different types of sport events to improve generalizability of the results. This study then attempts to classify the motivation-based profiles of sport event volunteers and develop a meaningful segmentation of volunteers across these sport events to verify more segmentation types and explore the characteristics of volunteers in various sport events.

\section{Methods}

The methods section describes how the study was conducted, why specific procedures were chosen, and explains how the data were analyzed. This section includes: (1) sampling frame; (2) instruments; (3) data collection and procedures; and, (4) treatment and analysis of data.

\subsection{Sampling frame}

This study contains a sample of volunteers from three separate sport events: the 2015 Australian PGA Championship event at the Gold Coast (Golf Tournament); the 2016 Gold Coast Airport Marathon event (Multi distance running event); and, the 2016 Cycle Queensland event (Long distance, multi day Cycling event). The golf and marathon events are both staged in a major tourism destination in Australia and are important components of the destination experience for tourists visiting the region. The cycling event was participant oriented but also a tourism 
experience to the extent that the participants and volunteers toured through and stayed in a number of different locations during the event. These three events were chosen for several reasons. First, because of time and financial constraints and bearing in mind the need for easy access to event organizers and event volunteers, this study selected event locations close to the researcher rather than choose events in other countries or regions. Second, each of these events is well-established (e.g. the PGA since 1905, the Marathon since 1979, and the Cycling since 2002), meaning that management structures and processes were likely to be well-established and that a mix of continuing and new volunteers would be involved in the event. Third, these events are heavily reliant on volunteers and they have few limitations on age, gender and socioeconomic status, making access to a potentially diverse group of volunteers possible. Such diverse sampling across different types of sport events attempted to address one of the shortcomings of the segmentation research referred to in the literature; that is, other studies have been limited to a single event. It is hoped that the current study will contribute to the development of this important and emerging body of knowledge on sport event volunteer segmentation by providing evidence of generalizability beyond a single mega-event to a range of smaller sport events.

In an effort to establish a basis for pooling the response data from three different sport events, the bivariate correlation matrices for each event were visually observed and compared for similarity. Comparable patterns were identified. Afterward, the pooled correlation matrix was inspected for intercorrelations. All statements were found to be correlated significantly $(r>0.4)$ with at least two other items. It was therefore determined that the pooled data set was suitable for analysis.

The size of the initial sampling frame was 668 (i.e. PGA: $n=350$, Marathon: $n=195$, and Cycling: $n=123$ ) and a useable sample for the analysis included 337 (i.e. PGA: $n=152$, Marathon: $\mathrm{n}=104$, and Cycling: $\mathrm{n}=81$ ) volunteers in total and resulted in an overall response rate of $50.4 \%$. 


\subsection{Instruments}

The survey questionnaire consisted of three parts: (1) items measuring volunteer motivations, (2) socio-demographic information, and (3) volunteering experiences. The questionnaire used for this study was adapted from the volunteer motivation study of Bang et al. (2009), which examined seven dimensions of volunteer motivation in a sport event context. The seven dimensions of VMS-ISE were Expression of Values (three items), Community Involvement (three items), Interpersonal Contacts (three items), Career Orientation (three items), Personal Growth (three items), Extrinsic Rewards (three items), and Love of Sport (three items). A pilot study using a convenience sample of 36 participants was conducted. According to the comments offered by the participants, the questionnaire was revised to improve the ease of reading and understanding.

Respondents were asked to indicate their levels of motivation, socio-demographic information, and volunteering experiences. The 21 items addressing motivation were measured on a unidirectional 5-point Likert-type scale $(1=$ not important, $2=$ slightly important, $3=$ somewhat important, $4=$ very important, $5=$ extremely important). For this research, five questions addressing socio-demographic information (e.g. gender, age, marital status, employment status, and educational level) and an additional five questions addressing volunteering experiences (e.g. previous volunteer experiences at this event and other events, main information source, volunteer position preference, and volunteer hours) were asked.

\subsection{Data collection and procedures}

A total of 668 volunteers were asked either in person or via email to complete the questionnaire. One or two weeks before the start of each event, a survey invitation email was sent to potential volunteers by volunteer coordinators of the three events, using their database of volunteers registered for these events. Four days later a reminder email was sent via the volunteer coordinator in an effort to improve response rates. Volunteers who were not able to participate 
in the online survey were asked by a member of the research team to complete a hard copy of the survey during the early stages of each event.

\subsection{Treatment and analysis of data}

The data collected from all three events were coded and analyzed using SPSS version 22. First, an exploratory factor analysis (EFA) was conducted using the PCA with a varimax rotation. EFA was used to explore the number of latent constructs underlying the set of items in regard to motivation and to provide a means of explaining variation among items. EFA is likely to examine processes for determining an appropriate number of factors and the pattern of factor loadings from the data. EFA is used when the primary goal is to identify latent constructs and there is relatively little prior theory and a lack of empirical evidence to specify an a priori model or make strong assumptions about how many common factors exist (Fabrigar, Wegener, MacCallum, \& Strahan, 1999).

In this study, the results of the EFA were quite different from those of previous empirical research which had used similar motivation scale items. Trninić, Jelaska, and Štalec (2013, p.13) stated that "Known structures of factors are frequently not corroborated by empirical research, that is, the same factors have not been found in different empirical factorial findings". In this way, although motivation variables used in this study were measured in previous studies, the common factors were slightly different as the targeted samples were somewhat unique and there was a risk respondents might understand and answer the questionnaire differently in each event context.

All factors with an eigenvalue equal to or greater than 1.0 were retained. In addition, all items with a factor loading equal to or above 0.6 and communality equal to or above 0.5 were included (see Table 2). Reliability coefficients (Cronbach's $\alpha$ ) were computed to estimate the internal consistency of the items within each factor. All factors identified in this study had reliability coefficients greater than 0.7 and were considered acceptable for further analysis. 
Second, this research investigated different groupings of respondents based on their motivations. Cluster analysis is used to identify motivational segments statistically through dividing individuals into relatively homogeneous subgroups based on their scores on the motivational items. Before conducting a cluster analysis, the raw motivation variables were standardized using Z-scores based on each individual means and standard deviation across the motivation items. The rationale for using standardization was to remove the influence of response style, that is, the tendency for some respondents to use the extreme ends of the scale while others tend to select values closer to the middle. By using a $Z$ - Score the new values reflect a relatively high or low score for any given respondent. A hierarchical cluster analysis was performed using Ward's method with squared Euclidean distance as the measure. To compare different groups of respondents regarding their motivation factors, frequency analysis was conducted based on the cluster solution by using variables saved as scores, which were formed by an EFA of motivation.

Third, chi-square tests were undertaken to test for significant relationships with regard to sociodemographic, volunteering-related experiences, and sport event types among the volunteer motivation subgroup clusters identified.

\section{Results}

Results of analysis are reported in terms of: (1) factor analysis of the motivation scale; (2) decision for the logical clustering; (3) profiles of motivational clusters; (4) characteristics of motivational clusters; and, (5) sport event types of motivational clusters.

\subsection{Factor analysis of the motivation scale}

The PCA of the 19 motivation items (of a total 21 items) resulted in six underlying dimensions. Two items (i.e. 'volunteering makes me feel needed' and 'volunteering makes me feel important') were omitted due to high cross-loadings between factors. These six factors were labelled (1) 'Expression of values', (2) 'Career orientation', (3) 'Love of sport', (4) 'Community involvement', (5) 'Interpersonal contacts', and (6) 'Extrinsic rewards' (see Table 2). 
Table 2: Factor analysis of motivation $(\mathrm{n}=337)$

\begin{tabular}{|c|c|c|c|c|c|}
\hline & Communality & $\begin{array}{c}\text { Rotated factor } \\
\text { loadings }\end{array}$ & Eigenvalue & $\begin{array}{c}\% \text { of Variance } \\
\text { explained }\end{array}$ & $\begin{array}{c}\text { Reliability } \\
(\text { Cronbach's } \alpha) \\
\end{array}$ \\
\hline $\begin{array}{l}\text { F1 Expression of Values } \\
(\text { Mean }=3.68 ; S D=0.96)\end{array}$ & & & 6.289 & 33.101 & .807 \\
\hline $\begin{array}{l}\text { I feel it is important to help } \\
\text { others. }\end{array}$ & .818 & .883 & & & \\
\hline $\begin{array}{l}\text { Volunteering creates a better } \\
\text { society. }\end{array}$ & .823 & .866 & & & \\
\hline $\begin{array}{l}\text { Volunteering allows me to gain } \\
\text { a new perspective on things. }\end{array}$ & .661 & .683 & & & \\
\hline $\begin{array}{l}\text { I want to do something } \\
\text { worthwhile. }\end{array}$ & .559 & .626 & & & \\
\hline $\begin{array}{l}\text { F2 Career Orientation } \\
\text { (Mean }=1.69 ; \mathrm{SD}=1.18)\end{array}$ & & & 2.976 & 15.661 & .883 \\
\hline $\begin{array}{l}\text { I want to gain work-related } \\
\text { experience. }\end{array}$ & .865 & .895 & & & \\
\hline $\begin{array}{l}\text { Volunteering experience will } \\
\text { look good on my résumé. }\end{array}$ & .841 & .883 & & & \\
\hline $\begin{array}{l}\text { I want to make new contacts } \\
\text { that might help my business or } \\
\text { career. }\end{array}$ & .769 & .829 & & & \\
\hline $\begin{array}{l}\text { F3 Love of Sport } \\
(\text { Mean=3.24; SD=1.27) }\end{array}$ & & & 2.006 & 10.558 & .876 \\
\hline Sport is something I love. & .863 & .894 & & & \\
\hline I like any event related to sport. & .816 & .860 & & & \\
\hline $\begin{array}{l}\text { I like any event related to this } \\
\text { sport. }\end{array}$ & .777 & .831 & & & \\
\hline $\begin{array}{l}\text { F4 Community Involvement } \\
(\text { Mean }=2.86, \mathrm{SD}=1.31)\end{array}$ & & & 1.414 & 7.443 & .893 \\
\hline $\begin{array}{l}\text { This sport event will raise the } \\
\text { prestige of my community. }\end{array}$ & .780 & .829 & & & \\
\hline $\begin{array}{l}\text { I am proud of my community } \\
\text { hosting this sport event. }\end{array}$ & .873 & .809 & & & \\
\hline $\begin{array}{l}\text { I want to express my pride in } \\
\text { my community. }\end{array}$ & .850 & .776 & & & \\
\hline $\begin{array}{l}\text { F5 Interpersonal Contacts } \\
\text { (Mean=3.02: } \mathrm{SD}=1.13 \text { ) }\end{array}$ & & & 1.029 & 5.418 & .846 \\
\hline I want to interact with others. & .826 & .838 & & & \\
\hline $\begin{array}{l}\text { I want to develop relationships } \\
\text { with others. }\end{array}$ & .799 & .826 & & & \\
\hline $\begin{array}{l}\text { I want to work with different } \\
\text { people. }\end{array}$ & .694 & .668 & & & \\
\hline $\begin{array}{l}\text { F6 Extrinsic Rewards } \\
(\text { Mean }=1.52 ; S D=0.95)\end{array}$ & & & 1.005 & 5.290 & .774 \\
\hline $\begin{array}{l}\text { I want to get tickets/free } \\
\text { admission. }\end{array}$ & .755 & .857 & & & \\
\hline $\begin{array}{l}\text { I want to get the event } \\
\text { uniform/licensed apparel. }\end{array}$ & .742 & .849 & & & \\
\hline $\begin{array}{l}\text { I want to get free food at the } \\
\text { event. }\end{array}$ & .610 & .734 & & & \\
\hline \multicolumn{3}{|l|}{ Total variance explained } & & 77.470 & \\
\hline \multicolumn{6}{|c|}{$\begin{array}{l}\text { Extraction Method: Principal Component Analysis. Rotation Method: Varimax with Kaiser Normalization. } \\
\text { Rotation converged in } 6 \text { iterations. } \\
\text { Measure of sampling adequacy: KMO } 0.839 \\
5 \text {-point Likert scale (1= not important, } 2=\text { slightly important, } 3=\text { somewhat important, } 4=\text { very important, } 5= \\
\text { extremely important) }\end{array}$} \\
\hline
\end{tabular}

The resulting solution identified six factors and explained $77.47 \%$ of the variance. Factor

loadings for all 19 items ranged from 0.626 to 0.895 . Relatively high factor loadings indicate a 
reasonably high relationship between the described factors and their individual items. Variables with low factor loadings were not observed after the two cross-loading items were dropped from the analysis. Reliability coefficients (Cronbach's $\alpha$ ) of all relevant variables in the rotated factor matrix ranged from 0.774 to 0.893 .

The first factor of 'Expression of values' (eigenvalue=6.289) consisted of four motivation items and the second factor of 'Career orientation' (eigenvalue=2.976) contained three items. The third factor of 'Love of sport' (eigenvalue=2.006) included three items, the fourth factor of 'Community involvement' (eigenvalue $=1.414$ ) also comprised three items, and the fifth factor of 'Interpersonal contacts' (eigenvalue=1.029) consisted of a further three motivation items. Finally, the sixth factor of 'Extrinsic rewards' (eigenvalue=1.005) included another three items. Six factors loaded in this study were somewhat different from those of previous studies which had used a similar event volunteer motivation scale (e.g. Bang \& Ross, 2009; Bang et al., 2009; Schlesinger \& Gubler, 2016). The previous studies extracted seven factors from the VMS-ISE scale using nearly 30 items, including not only the six factors loaded in this study, but also one factor which was 'personal growth'. However, due to omission of two items relating to the 'personal growth' factor that resulted from factor analysis in this study, six dimensions of volunteer motivation were finally determined.

\subsection{Decision for the logical clustering}

Cluster analysis can be used to identify which cases in a data set are similar, based on the centroids of a set of variables. Cluster analysis allows researchers to identify a range of cluster solutions and then to select the best solution based on ease of interpretation. Although many researchers use factor score in the cluster analysis, Dolnicar and Grün (2008) argued that this approach is less likely to determine the logical cluster solution because important variation in the dataset is lost.

For instance, a study by Cha, McCleary, and Uysal (1995) used six factor scores which explained only $50 \%$ of variance in the original 30 motivational items. Shoemaker (1994) also 
used the resulting factor scores in only 12 factors from the original 39 items. The study by Alexander et al. (2015) used the mean values of seven factor scores from an original 21 items addressing motivation to conduct a k-means clustering procedure. Likewise, there are several problems regarding the procedure for using factor scores in segmentation studies. It can lead to different results against the original information and discard information before cluster analysis. Also, it can eliminate variables that potentially could be the most important pieces of information for the identification of ideal segments (Dolnicar \& Grün, 2008) Therefore, researchers should question this procedure when performing segmentation studies.

Sheppard (1997, p.57) suggested that "Cluster analysis on raw item scores, as opposed to factor scores, may produce more accurate or detailed segmentation as it preserves a greater degree of the original data". Although it may be difficult to demonstrate an appropriate segmentation technique as it is typically not known which the true segment solution is (Dolnicar \& Grün, 2008), overall clustering of the raw data directly (i.e. cluster segmentation) can identify the number of clusters in the data set more correctly than cluster analysis, using the resulting factor scores (i.e. factor-cluster segmentation). In this regard, 'factor-cluster segmentation' tends to perform substantially worse than 'cluster segmentation' as an approach of 'factor-cluster segmentation' may reduce the success of segment solution (Dolnicar \& Grün, 2008) and may ignore critical information from respondents. Consistent with this line of reasoning, this study used the original item scores for the cluster analysis rather than the factor scores.

The next decision was to use standardized data rather than unstandardized data for the cluster analysis. In this study, each item was measured on a five point Likert-type scale and the distribution of motivation scores demonstrated low levels of variance; therefore raw scores were standardized using Z-scores so that each respondent motivation score represented its deviation from the mean of all their motivation scores rather than a specific point on the scale. Although the choice of a certain standardization rule is up to the discretion of the researcher (Visalakshi \& Thangavel, 2009), a standardization procedure seems to make a better quality cluster solution. Thus, Z-scores were used in this study. 
Finally, the clustering method selected was hierarchical cluster analysis using Ward's method with squared Euclidian distances as the measure. There are many possible applications of clustering techniques, the most common ones being k-means and hierarchical clustering algorithms (Johnson, 1967). "Hierarchical clustering is a step-wise process that merges the two closest or furthest data points or group of data points at each step" (Cabieses, Tunstall, \& Pickett, 2015, p.309). Ward's method of hierarchical clustering with squared Euclidean distance is said to identify groups clearly by minimizing within cluster differences and avoiding problems in regard to chaining of observations found in the single linkage method (Hair, Anderson, Tatham, \& Black, 1998).

\subsection{Profiles of motivational clusters}

All of the scores of the standardized raw motivation variables were used in the cluster analysis to determine the profiles of sport event volunteers. After analyzing the cluster solutions ranging from two to five clusters, a four-cluster solution was selected to be the most adequate due to meaningful differences between the segments. The total sample $(n=337)$ was compared in the four-cluster solution and had different sized groups. The results of the final cluster analysis procedure are displayed in Table 3. Cluster 1 accounted for 41 out of 337 volunteers $(12.2 \%$ of cases) while Cluster 2 was the largest segment with 165 volunteers ( $49.0 \%$ of cases). Cluster 3 was the second largest and accounted for 95 volunteers (28.1\% of cases) and Cluster 4 was the smallest group including only 36 volunteers $(10.7 \%)$. The factor scores from the PCA were then used to describe the profiles of each cluster.

Table 3: Hierarchical cluster analysis on standardized motivation variables $(\mathrm{n}=337)$

\begin{tabular}{lcccc}
\hline Factor & $\begin{array}{c}\text { Cluster 1 } \\
\text {-material } \\
\text { benefits seekers } \\
(\mathrm{n}=41 / 12.2 \%)\end{array}$ & $\begin{array}{c}\text { Cluster 2 } \\
\text {-sport and } \\
\text { community } \\
\text { enthusiasts } \\
(\mathrm{n}=165 / 49.0 \%)\end{array}$ & $\begin{array}{c}\text { Cluster } 3 \\
\text {-altruists } \\
(\mathrm{n}=95 / 28.1 \%)\end{array}$ & $\begin{array}{c}\text { Cluster } 4 \\
\text {-career and social } \\
\text { relationship } \\
\text { seekers } \\
(\mathrm{n}=36 / 10.7 \%)\end{array}$ \\
\hline Expression of Values & -1.01 & 0.16 & $\mathbf{0 . 2 4}$ & -0.24 \\
Career Orientation & -0.51 & -0.04 & -0.47 & $\mathbf{2 . 0 1}$ \\
Love of Sport & 0.15 & $\mathbf{0 . 1 9}$ & -0.23 & -0.45 \\
Community Involvement & -0.21 & $\mathbf{0 . 7 1}$ & -0.88 & -0.69 \\
Interpersonal Contacts & -0.53 & -0.05 & 0.20 & $\mathbf{0 . 3 1}$ \\
Extrinsic Rewards & $\mathbf{1 . 1 9}$ & -0.21 & -0.21 & 0.16 \\
\hline
\end{tabular}

Highest cluster scores across groups are boldfaced. 
Cluster 1 was highest for the factor 'Extrinsic rewards' (1.19) across groups. Cluster 2 displayed the highest mean cluster scores for the factors of 'Love of sport' $(0.19)$ and 'Community involvement' (0.71). 'Expression of Values' (0.24) was the highest motivation factor for Cluster 3 compared to other clusters, and Cluster 4 was highest on the factors 'Career orientation' (2.01) and 'Interpersonal contacts' (0.31). In the following section, the four clusters are described by the positive and high scores of motivation factors based on the cluster solution on the standardized motivation values.

Cluster $1(12.2 \%)$ was strongly motivated by 'Extrinsic rewards' as the most positive within this cluster and was labeled 'material benefits seekers' because it included incentives that fit into the material/utilitarian incentives described by Knoke and Prensky (1984). Through their volunteering activity, these individuals mostly sought tangible benefits rather than intangible benefits or values. They expected to receive the material rewards such as free tickets/admission, uniform, licensed apparel, and food. Interestingly, volunteers in this group were generally not motivated by the factor 'Expression of Values' (-1.01) which had the highest negative motivation score for this cluster and across all four clusters.

Cluster 2 (49.0\%) was characterized by the high positive motivation factor, 'Community involvement', and the second highest positive motivation factor, 'Love of sport', within this group. It was labeled 'sport and community enthusiasts'. This group involved sport-specific incentives and coincided with the sport fan involvement approach, grounded in social identity theory (e.g. Jenkins, 1996; Laverie \& Arnett, 2000; MacClancy, 1996). Volunteers in this group were motivated by getting involved in the volunteering to express and present their love and pride in terms of sport and their community hosting the sport event. It can be argued that this group had a tendency to be altruistic and, interestingly, the factor 'Extrinsic rewards' $(-0.21)$, on the contrary, had a relatively low value for these volunteers.

Cluster 3 (28.1\%) was mainly oriented towards the motivation factor 'Expression of Values'. This group was named 'altruists' and scored highly on altruistic values, what Knoke and 
Prensky (1984) called normative/purposive incentives. Volunteers in this group considered purposive motives to be the most important in order to help others and create a better society. However, they had relatively low scores on the 'Community involvement' (-0.88) factor which tends to be inconsistent with altruistic value.

Cluster $4(10.7 \%)$ volunteers were motivated to meet and interact with other people and gain new career contacts for their jobs. The motivation factors 'Career orientation' and 'Interpersonal contacts' were both relatively highly scored for this group of volunteers. This group was named 'career and social relationship seekers' and was similar to Knoke and Prensky's (1984) affective/solidary incentives. Volunteers in Cluster 4 used the sport events to develop a social network and develop career-related experiences. In contrast, the factor 'Community involvement' (-0.69) tended to have less importance as a driver of their motivation.

\subsection{Characteristics of motivational clusters}

To compare and distinguish the four motivational clusters, the four groups were analyzed with regard to social-demographic and volunteering-related experiences using Chi-Square Contingency Table Analysis. This analysis identifies patterns that are likely to enable sport event organizations to better understand the profile of volunteers' characteristics and support the development of strategies that could be used to better target the recruitment of potential volunteers.

Chi-square tests were used to identify relationships between the socio-demographic variables and membership of each cluster (see Table 4). 
Table 4: Socio-demographic characteristics of motivational clusters $(n=337)$

\begin{tabular}{|c|c|c|c|c|c|c|}
\hline Characteristic & $\begin{array}{l}\text { Cluster } 1 \\
\text {-material } \\
\text { benefits } \\
\text { seekers } \\
(\mathrm{n}=41 / \\
12.2 \%)\end{array}$ & $\begin{array}{l}\text { Cluster } 2 \\
\text {-sport and } \\
\text { community } \\
\text { enthusiasts } \\
(\mathrm{n}=165 / \\
49.0 \%)\end{array}$ & $\begin{array}{l}\text { Cluster } 3 \\
\text {-altruists } \\
(\mathrm{n}=95 / \\
28.1 \%)\end{array}$ & $\begin{array}{l}\text { Cluster } 4 \\
\text {-career and } \\
\text { social } \\
\text { relationship } \\
\text { seekers } \\
(\mathrm{n}=36 / 10.7 \%)\end{array}$ & $\begin{array}{l}\begin{array}{l}\text { Total } \\
(\mathrm{n}=337 /\end{array} \\
100 \%)\end{array}$ & Statistics \\
\hline \multicolumn{7}{|l|}{ Gender } \\
\hline Male & $23(56.1 \%)$ & $98(59.4 \%)$ & $53(55.8 \%)$ & $22(66.1 \%)$ & $196(58.2 \%)$ & $X^{2}=0.52$ \\
\hline Female & $18(43.9 \%)$ & $67(40.6 \%)$ & $42(44.2 \%)$ & $14(38.9 \%)$ & $141(41.8 \%)$ & $p=n s$ \\
\hline \multicolumn{7}{|l|}{ Age } \\
\hline$<30$ & $1(2.4 \%)$ & $8(4.8 \%)$ & $4(4.2 \%)$ & $24(66.7 \%)$ & $37(11.0 \%)$ & \multirow{4}{*}{$\begin{array}{l}X^{2}=162.03 ; \\
p<0.001\end{array}$} \\
\hline $30-44$ & $2(4.9 \%)$ & $13(7.9 \%)$ & $5(5.3 \%)$ & $8(22.2 \%)$ & $28(8.3 \%)$ & \\
\hline $45-64$ & $23(56.1 \%)$ & $58(35.2 \%)$ & $53(55.8 \%)$ & $4(11.1 \%)$ & $138(40.9 \%)$ & \\
\hline 65 or above & $15(36.6 \%)$ & $86(52.1 \%)$ & $33(34.7 \%)$ & $0(0.0 \%)$ & $134(39.8 \%)$ & \\
\hline \multicolumn{7}{|l|}{ Partnership } \\
\hline Yes & $31(75.6 \%)$ & $110(66.7 \%)$ & $75(78.9 \%)$ & $5(13.9 \%)$ & $221(65.6 \%)$ & \multirow{2}{*}{$\begin{array}{l}X^{2}=52.05 \\
p<0.001\end{array}$} \\
\hline No & $10(24.4 \%)$ & $55(33.3 \%)$ & $20(21.1 \%)$ & $31(86.1 \%)$ & $116(34.4 \%)$ & \\
\hline \multicolumn{7}{|l|}{ Employment Status } \\
\hline Work full-time & $8(19.5 \%)$ & $25(15.2 \%)$ & $23(24.2 \%)$ & $7(19.4 \%)$ & $63(18.7 \%)$ & \multirow{4}{*}{$\begin{array}{l}X^{2}=82.74 \\
p<0.001\end{array}$} \\
\hline Work part-time & $9(22.0 \%)$ & $26(15.8 \%)$ & $20(21.1 \%)$ & $14(38.9 \%)$ & $69(20.5 \%)$ & \\
\hline Retired & $22(53.7 \%)$ & $103(62.4 \%)$ & $50(52.6 \%)$ & $0(0.0 \%)$ & $175(51.9 \%)$ & \\
\hline Unemployed & $2(4.9 \%)$ & $11(6.7 \%)$ & $2(2.1 \%)$ & $15(41.7 \%)$ & $30(8.9 \%)$ & \\
\hline \multicolumn{7}{|l|}{ Educational level } \\
\hline Secondary or below & $9(22.0 \%)$ & $33(20.0 \%)$ & $21(22.1 \%)$ & $0(0.0 \%)$ & $63(18.7 \%)$ & \multirow{3}{*}{$\begin{array}{l}X^{2}=32.55 \\
p<0.001\end{array}$} \\
\hline $\begin{array}{l}\text { Technical or further } \\
\text { education institution }\end{array}$ & $9(22.0 \%)$ & $62(37.6 \%)$ & $23(24.2 \%)$ & $3(8.3 \%)$ & $97(28.8 \%)$ & \\
\hline $\begin{array}{l}\text { University or tertiary } \\
\text { institution }\end{array}$ & $23(56.1 \%)$ & $70(42.4 \%)$ & $51(53.7 \%)$ & $33(91.7 \%)$ & $177(52.5 \%)$ & \\
\hline
\end{tabular}

There were no significant relationships with gender among the four clusters as $p>0.05$ $\left(X^{2}=0.52\right)$. All clusters tended to have a balanced gender distribution with a slightly higher proportion of males due to their over-representation in the sample (58.2\%). However, there were significant age patterns $\left(X^{2}=162.03 ; p<0.001\right)$ between the groups. Cluster 1 (material benefits seekers) and Cluster 3 (altruists) were dominated by people aged 45 to 64, while Cluster 4 (career and social relationship seekers) had more people ( $<30$ years of age; 66.7\%). People aged 65 or above were comparatively affiliated with Cluster 2 (sport and community enthusiasts) (52.1\%). Results in terms of partnership types of the volunteers indicated that there were significant relationships $\left(X^{2}=52.05 ; p<0.001\right)$. Volunteers who were married or living with a partner were predominantly found in Cluster 1 (material benefits seekers) $(75.6 \%)$, Cluster 2 (sport and community enthusiasts) (66.7\%), and Cluster 3 (altruists) (78.9\%). Perhaps not surprisingly, Cluster 4 (career and social relationship seekers) was most likely to involve singles $(86.1 \%)$ as people aged $<30$ years mostly belonged to this cluster. With regard to employment status $\left(X^{2}=82.74 ; p<0.001\right)$, volunteers in Cluster 4 (career and social relationship seekers) 
were mostly unemployed $(41.7 \%)$ or people with a part-time job (38.9\%). There were no retired people in this cluster. On the contrary, volunteers in Cluster 1 (material benefits seekers)

(53.7\%), Cluster 2 (sport and community enthusiasts) (62.4\%), and Cluster 3 (altruists) $(52.6 \%)$ were predominantly retired people. Although findings regarding socio-demographic features found significant patterns in educational level $\left(X^{2}=32.55 ; p<0.001\right)$, all clusters seemed to have a generally high level of education equal to University or tertiary institution. Almost all volunteers in Cluster 4 (career and social relationship seekers) (91.7\%) were tertiary educated which may be related to the age distribution in that two-thirds of volunteers in Cluster 4 (career and social relationship seekers) were people aged less than 30 years.

Volunteering experience characteristics also indicated significant differences between volunteer groups (see Table 5).

Table 5: Volunteering experience characteristics of motivational clusters $(\mathrm{n}=337)$

\begin{tabular}{|c|c|c|c|c|c|c|}
\hline Characteristic & $\begin{array}{l}\text { Cluster } 1 \\
\text {-material } \\
\text { benefits } \\
\text { seekers } \\
(\mathrm{n}=41 / \\
12.2 \%) \\
\end{array}$ & $\begin{array}{l}\text { Cluster } 2 \\
\text {-sport and } \\
\text { community } \\
\text { enthusiasts } \\
(\mathrm{n}=165 / \\
49.0 \%)\end{array}$ & $\begin{array}{c}\text { Cluster } 3 \\
\text {-altruists } \\
(\mathrm{n}=95 / \\
28.1 \%)\end{array}$ & $\begin{array}{l}\text { Cluster } 4 \\
\text {-career and } \\
\text { social } \\
\text { relationship } \\
\text { seekers } \\
(n=36 / 10.7 \%)\end{array}$ & $\begin{array}{l}\text { Total } \\
(\mathrm{n}=337 / \\
100 \%)\end{array}$ & Statistics \\
\hline \multicolumn{7}{|c|}{ Volunteer experiences at this sport event } \\
\hline None & $22(53.7 \%)$ & $48(29.1 \%)$ & $34(35.8 \%)$ & $28(77.8 \%)$ & $132(39.2 \%)$ & \multirow{4}{*}{$\begin{array}{l}X^{2}=36.82 \\
p<0.001\end{array}$} \\
\hline $1-2$ & $5(12.2 \%)$ & $43(26.1 \%)$ & $21(22.1 \%)$ & $5(13.9 \%)$ & $74(22.0 \%)$ & \\
\hline $3-4$ & $9(22.0 \%)$ & $37(22.4 \%)$ & $20(21.1 \%)$ & $3(8.3 \%)$ & $69(20.5 \%)$ & \\
\hline 5 or above & $5(12.2 \%)$ & $37(22.4 \%)$ & $20(21.1 \%)$ & $0(0.0 \%)$ & $62(18.4 \%)$ & \\
\hline \multicolumn{7}{|c|}{ Volunteer experiences at other events } \\
\hline None & $16(39.0 \%)$ & $29(17.6 \%)$ & $24(25.3 \%)$ & $8(22.2 \%)$ & $77(22.8 \%)$ & \multirow{3}{*}{$\begin{array}{l}X^{2}=22.50 ; \\
p<0.05\end{array}$} \\
\hline $1-3$ & $15(36.6 \%)$ & $63(38.2 \%)$ & $38(40.0 \%)$ & $16(44.4 \%)$ & $132(39.2 \%)$ & \\
\hline 4 or above & $10(24.4 \%)$ & $73(44.2 \%)$ & $33(34.7 \%)$ & $12(33.3 \%)$ & $128(38.0 \%)$ & \\
\hline \multicolumn{7}{|c|}{ Main information source } \\
\hline Family & $5(12.2 \%)$ & $5(3.0 \%)$ & $9(9.5 \%)$ & $1(2.8 \%)$ & $20(5.9 \%)$ & \multirow{6}{*}{$\begin{array}{l}X^{2}=25.62 ; \\
p<0.05\end{array}$} \\
\hline Friend & $8(19.5 \%)$ & $35(21.2 \%)$ & $20(21.1 \%)$ & $3(8.3 \%)$ & $66(19.6 \%)$ & \\
\hline Internet website & $10(24.4 \%)$ & $53(32.1 \%)$ & $29(30.5 \%)$ & $18(50.0 \%)$ & $110(32.6 \%)$ & \\
\hline Referred by staff & $4(9.8 \%)$ & $24(14.5 \%)$ & $10(10.5 \%)$ & $4(11.1 \%)$ & $42(12.5 \%)$ & \\
\hline Through community & $8(19.5 \%)$ & $16(9.7 \%)$ & $9(9.5 \%)$ & $8(22.2 \%)$ & $41(12.2 \%)$ & \\
\hline Other $^{1}$ & $6(14.6 \%)$ & $32(19.4 \%)$ & $18(18.9 \%)$ & $2(5.6 \%)$ & $58(17.2 \%)$ & \\
\hline \multicolumn{7}{|c|}{ Volunteer position preference } \\
\hline Other position & $4(9.8 \%)$ & $7(4.2 \%)$ & $6(6.3 \%)$ & $8(22.2 \%)$ & $25(7.4 \%)$ & \multirow{3}{*}{$\begin{array}{l}X^{2}=18.21 ; \\
p<0.05\end{array}$} \\
\hline No preference & $15(36.6 \%)$ & $64(38.8 \%)$ & $41(43.2 \%)$ & $17(47.2 \%)$ & $137(40.7 \%)$ & \\
\hline Assigned position & $22(53.7 \%)$ & $94(57.0 \%)$ & $48(50.5 \%)$ & $11(30.6 \%)$ & $175(51.9 \%)$ & \\
\hline \multicolumn{7}{|c|}{ Volunteer hours at this sport event } \\
\hline \multicolumn{7}{|c|}{ Pre-event } \\
\hline None & $17(41.5 \%)$ & $52(31.5 \%)$ & $45(47.4 \%)$ & $5(13.9 \%)$ & $119(35.3 \%)$ & \multirow{3}{*}{$\begin{array}{l}X^{2}=28.11 ; \\
p<0.001\end{array}$} \\
\hline $1-5$ & $17(41.5 \%)$ & $53(32.1 \%)$ & $30(31.6 \%)$ & $9(25.0 \%)$ & $109(32.3 \%)$ & \\
\hline 6 or above & $7(17.1 \%)$ & $60(36.4 \%)$ & $20(21.1 \%)$ & $22(61.1 \%)$ & $109(32.3 \%)$ & \\
\hline \multicolumn{7}{|l|}{ During event } \\
\hline $0-10$ & $4(9.8 \%)$ & $44(26.7 \%)$ & $14(14.7 \%)$ & $17(47.2 \%)$ & $79(23.4 \%)$ & \multirow{3}{*}{$\begin{array}{l}X^{2}=26.56 \\
p<0.001\end{array}$} \\
\hline $11-30$ & $18(43.9 \%)$ & $66(40.0 \%)$ & $31(32.6 \%)$ & $11(30.6 \%)$ & $126(37.4 \%)$ & \\
\hline 31 or above & $19(46.3 \%)$ & $55(33.3 \%)$ & $50(52.6 \%)$ & $8(22.2 \%)$ & $132(39.2 \%)$ & \\
\hline \multicolumn{7}{|l|}{ Post-event } \\
\hline None & $35(85.4 \%)$ & $141(85.5 \%)$ & $85(89.5 \%)$ & $32(88.9 \%)$ & $293(86.9 \%)$ & \multirow{2}{*}{$\begin{array}{l}X^{2}=1.07 \\
p=n s\end{array}$} \\
\hline 1 or above & $6(14.6 \%)$ & $24(14.5 \%)$ & $10(10.5 \%)$ & $4(11.1 \%)$ & $44(13.1 \%)$ & \\
\hline
\end{tabular}


In regard to previous experiences at the sport events for which respondents volunteered (e.g. golf, marathon, and cycling in this study; $X^{2}=36.82 ; p<0.001$ ), Cluster 1 (material benefits seekers) (53.7\%), and Cluster 4 (career and social relationship seekers) $(77.8 \%)$ were dominated by first-time volunteers at these events. The other two clusters had an overall comparable proportion regarding distribution of volunteers from first time volunteers to experienced volunteers. Previous volunteer experiences at other events also varied amongst clusters $\left(X^{2}=22.50 ; p<0.05\right)$. Volunteers in Cluster 1 (material benefits seekers) tended to report no experience in event volunteering $(39.0 \%)$ or only a few previous experiences $(36.6 \%)$. In contrast, volunteers who had had experiences of volunteering at other events were more likely to belong to Cluster 2 (sport and community enthusiasts) (44.2\%). Volunteers who had a few volunteering experiences seemed to be well represented in Cluster 3 (altruists) (40.0\%) and Cluster 4 (career and social relationship seekers) (44.4\%). Although volunteers gained volunteering information through various ways, they were likely to search main information by internet website in the overall clusters $\left(X^{2}=25.62 ; p<0.05\right)$. Volunteers in Cluster 4 (career and social relationship seekers) especially tended to have a higher proportion of internet website use (50.0\%) compared to other information sources. In each of the clusters except Cluster 4 (career and social relationship seekers), more than half of the volunteers revealed that they were happy with the volunteer position they had been assigned $\left(X^{2}=18.21 ; p<0.05\right)$. Though Cluster 4 (career and social relationship seekers) had relatively fewer cases than other clusters, it was found that volunteers in Cluster 4 (career and social relationship seekers) did not have a strong preference for any specific volunteer position (47.2\%). Interestingly, the hours that volunteers worked indicated significant variation, depending on the time of involvement. Before starting the event $\left(X^{2}=28.11 ; p<0.001\right)$, volunteers in Cluster 2 (sport and community enthusiasts) and Cluster 4 (career and social relationship seekers) spent a relatively long time (at least six hours or more) doing their volunteer work (e.g. preparing the official events, volunteering at minor events before the main event). In contrast, volunteers in Cluster 1 (material benefits seekers) and Cluster 3 (altruists) were less likely to get involved in volunteering before the event. During the staging of the event $\left(X^{2}=26.56 ; \mathrm{p}<0.001\right)$, the majority of volunteers in Cluster 1 (material 
benefits seekers) and Cluster 3 (altruists), however, spent proportionally more time volunteering than volunteers in Cluster 2 (sport and community enthusiasts) and Cluster 4 (career and social relationship seekers). Cluster 4 (career and social relationship seekers) particularly, seemed to spend less than 10 hours working during the actual period of the event. Finally, there were no significant differences between clusters in terms of volunteer hours after the event $\left(X^{2}=1.07 ; \mathrm{p}=\right.$ ns). More than four-fifths of all volunteers in the study (86.9\%) did not participate in post-event volunteering. However, in many instances, there appeared to be no demand for volunteers to volunteer their time post-event.

\subsection{Sport event types of motivational clusters}

As this study includes a sample of volunteers from three different types of sport events (i.e. golf, marathon, and cycle), motivational clusters were analyzed using chi-square tests (see Table 6). There was a significant pattern among the four clusters with respect to types of sport events $\left(X^{2}=75.75 ; p<0.001\right)$. Cluster 1 (material benefits seekers), which was most likely to involve people aged 45 to 64 years and consisted predominantly of volunteers who engaged in the PGA golf event (80.5\%). In contrast, Cluster 4 members (career and social relationship seekers), which was dominated by people aged $<30$ years, tended to volunteer at the marathon event (75.0\%). Although volunteers at the cycling event were most evident in Cluster 3 (altruists) (37.9\%), they were quite evenly distributed across the four clusters when compared to those at the PGA and marathon events.

Table 6: Sport event types of motivational clusters $(n=337)$

\begin{tabular}{|c|c|c|c|c|c|c|}
\hline Sport event type & $\begin{array}{l}\text { Cluster } 1 \\
\text {-material } \\
\text { benefits } \\
\text { seekers } \\
(\mathrm{n}=41 / \\
12.2 \%)\end{array}$ & $\begin{array}{l}\text { Cluster } 2 \\
\text {-sport and } \\
\text { community } \\
\text { enthusiasts } \\
(n=165 / \\
49.0 \%)\end{array}$ & $\begin{array}{c}\text { Cluster } 3 \\
\text {-altruists } \\
(n=95 / \\
28.1 \%)\end{array}$ & $\begin{array}{l}\text { Cluster } 4 \\
\text {-career and } \\
\text { social } \\
\text { relationship } \\
\text { seekers } \\
(n=36 / 10.7 \%)\end{array}$ & $\begin{array}{l}\text { Total } \\
(n=337 / \\
100 \%)\end{array}$ & Statistics \\
\hline PGA & $33(80.5 \%)$ & $75(45.5 \%)$ & $43(45.3 \%)$ & $1(2.8 \%)$ & $152(45.1 \%)$ & $X^{2}=75.75$ \\
\hline Marathon & $2(4.9 \%)$ & $59(35.8 \%)$ & $16(16.8 \%)$ & $27(75.0 \%)$ & $104(30.9 \%)$ & $p<0.001$ \\
\hline Cycle & $6(14.6 \%)$ & $31(18.8 \%)$ & $36(37.9 \%)$ & $8(22.2 \%)$ & $81(24.0 \%)$ & \\
\hline
\end{tabular}




\section{Discussion and Conclusion}

This study identifies the motivations of volunteers for specific sport events in Queensland, including the 2015 Australian PGA Championship, the 2016 Gold Coast Airport Marathon, and the 2016 Cycle Queensland event. Also, this study analyzes the data to identify relatively homogeneous clusters of volunteer motivations and to define characteristics of the clusters in terms of their members' socio-demographic status, volunteering-related experiences, and sport event types. A hierarchical cluster analysis using standardized variables is used to identify the logical cluster solution in order to classify profiles of volunteers based on their motivations and compare volunteer characteristics between these clusters. The results indicate that levels and factors of motivations are different amongst the four main groups and influence each characteristic of volunteers in the groups. The findings of this research have implications for both theory and practice. Research limitations and future research directions are discussed.

\section{Theoretical implications}

In terms of the theoretical implications, first, in an effort to increase generalizability of segmentation studies investigating sport event volunteers, the samples in this study involved volunteers from three different types of sport events. Consideration of the various samples shows that this study may contribute to the generalizability of the results by transferring to other types of sport events in Queensland, Australia as other segmentation studies on the motives of sport event volunteers were limited to a single mega sport event in Europe (e.g. Alexander et al., 2015; Schlesinger \& Gubler, 2016). Diverse sampling from different types of major sport events might be designed for application to non-mega sport events and thus contribute to the development of segmentation studies on sampling selection processes of relevance to all sport events.

Second, this study supported some of the previous research findings on measuring volunteers' motivations. The first motivation factor, 'expression of value', is very similar to the 'values' factor that Clary et al. (1998) described in their research, to the 'altruistic' factor in Monga's 
(2006) study, and to the 'purposive' factor reported by Farrell et al. (1998) and Giannoulakis et al. (2007). As many previous studies have identified this dimension, it appears that altruistic value is a common motive amongst sport event volunteers. Understanding of altruism can be drawn from a widely known definition of volunteering. The International Labor Organization (2011, p. 13) defined volunteer work as "unpaid non-compulsory work; that is, time individuals give without pay to activities performed either through an organization or directly for those outside their own household." The nature of the volunteering phenomenon is associated with why volunteers freely choose to help others with no remuneration such that the nature of the volunteering phenomenon in itself seems to be related to understanding of the concept of altruistic value.

The second motivation factor 'career orientation' accords with the 'career' factor described by Clary et al. (1998) and the 'instrumentalist' factor identified by Monga (2006). This factor was identified as a motive that is shared among several studies on volunteer motivation (e.g. Bang et al., 2008; Bang \& Ross, 2009; Bang et al., 2009; Clary et al., 1998; Hallmann \& Harms, 2012; Schlesinger \& Gubler, 2016; VanSickle et al., 2015). Volunteers may seek to address personal needs beyond altruistic values when volunteering for sport events. For example, individuals might want to volunteer to gain work-related experience and make new contacts for their business or career. The 'career' motive has emphasized volunteering as a response to initial work qualifications. This motive therefore has an influence primarily on volunteers who are still in the labor market, rather than on those who have retired.

The third motivation factor 'love of sport' and the fourth motivation factor 'community involvement' were identified as sport specific motives. These factors, measured by Bang and Ross (2009), can be unique motivations and goals of volunteers in terms of the sport. In the category of 'sport specific motives', the reasons for volunteering reflect the sport itself rather than a general desire such as helping others or establishing a social relationship. Individuals who have enthusiasm for sports and community might desire to express their love and interest in sports by being involved in volunteer activities related to sport. In this study, the majority of 
volunteers (cluster 2- sport and community enthusiasts) were highly motivated because they liked events related to sport and they wanted to express their pride in their community in hosting sport events.

The fifth motivation factor 'interpersonal contacts' has parallels with what Clary et al. (1998) named 'social', Farrell et al. (1998) and Monga (2006) called 'solidary', and Giannoulakis et al. (2007) called 'egoistic'. Volunteering has been a part of most societies throughout human history (Hodgkinson, 2003). The 'interpersonal contacts' factor illustrates that individuals enjoy forming social relationships and developing a social network to interact with other people and get involved in the society. That is, volunteering can provide opportunities for social interaction for volunteers who focus on 'belongingness' in a social network (Bang et al., 2008; Bang \& Ross, 2009; Bang et al., 2009; Dickson et al., 2013; Dickson et al., 2014; Hallmann \& Harms, 2012; Khoo \& Engelhorn, 2011; Schlesinger \& Gubler, 2016; Twynam et al., 2002; VanSickle et al., 2015).

The sixth motivation factor, 'extrinsic rewards' linked to 'instrumentalist' factor demonstrated by Monga (2006), refers to tangible and material benefits. In this study, this dimension was found to be valuable in motivating volunteers to provide their services in exchange for material benefits. Such exchange may be for tangible and symbolic rewards. Cluster 1 (material benefits seekers) had relatively high levels of motivation for extrinsic rewards, which contrasted with low levels of intrinsic motivation. The volunteers' desires to receive extrinsic rewards such as material benefits, conditions of work and service, and materials given by the organization, seems to play an important role in making them more engaged in the sport event. If volunteers are influenced more by extrinsic benefits, a motivational force will occur through extrinsic motivation rather than intrinsic motivation.

Third, this study confirmed the incentives approach of motivation described by Knoke and Prensky (1984) and the sports fan involvement approach grounded in social identity theory used by Jenkins (1996), Laverie and Arnett (2000), and MacClancy (1996). The four sport event 
volunteer clusters based on motivation were differentiated in terms of their socio-demographic and volunteering experiences characteristics. Cluster 1, motivated by 'extrinsic rewards', can be explained by the material/utilitarian incentives approach in Knoke and Prensky's (1984) study and members of Cluster 1 are referred to as 'material benefits seekers'. Cluster 2, high on the motivation factor of 'community involvement' and 'love of sport', represents a sports fan involvement approach grounded in social identity theory; and 'sport and community enthusiasts' belong to this group as they are mostly influenced by sport specific incentives. Cluster 3, labeled 'altruists', support Knoke and Prensky's (1984) study, which suggests that volunteers have normative/purposive incentives to express one's altruistic and humanitarian concerns for others. Cluster 4, named 'career and social relationship seekers', illustrates the affective/solidary incentives approach to building and strengthening social interaction and relationships, according to Knoke and Prensky (1984). Drawing on the incentives approach of motivation (Knoke \& Prensky, 1984) and sports fan involvement research grounded in social identity theory (e.g. Jenkins, 1996; Laverie \& Arnett, 2000; MacClancy, 1996), this study has developed a clearer understanding of these four groups and identified aspects of volunteer motivation in sport events that might influence a better understanding of the volunteer segments.

\section{Practical implications}

Some practical implications can be derived from this research on the motivations of sport event volunteers. First, the high proportion of volunteers aged 45-65 years and above in Cluster 1 (material benefits seekers), Cluster 2 (sport and community enthusiasts), and Cluster 3 (altruists) indicated that it is important to try to recruit other people for volunteer roles at sport events in Queensland in the longer term. Although high engagement of volunteers aged over 45 years may not be a problem in the short term, consideration could be given to diversifying the volunteer base with a broad range of age or experience depending on the type of event, for the future. For example, younger volunteers could be attracted to events through contacting schools and emphasizing benefits such as enjoyment, work experience, resume development, and 
industry connections that would appeal to younger generations (cluster 4-career and social relationship seekers) who might be motivated to volunteer to improve their employability.

Second, with regard to employment status in each cluster, even though a high percentage of volunteers was either retired (cluster 1, 2, and 3) or unemployed (cluster 4), about $40 \%$ of volunteers were still working either part-time or full-time. Therefore, event organizers could consider flexible and appropriate volunteering schedules and workloads to accommodate these volunteers.

Third, although about $60 \%$ of the total volunteers had volunteered previously at the sport events, new volunteers still accounted for a considerable proportion of a total of volunteers. Therefore, event organizers may also consider providing a well-organized orientation program including volunteering role information and instructions when volunteers are gathered together, as players and spectators are likely to receive a better level of service from well-trained volunteers.

Fourth, as the main source of information for most volunteers was dominated by the internet in each cluster, it may be necessary for event organizers to develop an online system for easy access to information and registration of their interest in volunteering for an event. Also, volunteers had found out about volunteering at the sport events through their personal network or community (e.g. friends, staff). Event organizers may need to encourage existing volunteers to recommend potential volunteers.

Fifth, most volunteers in this study liked to feel that they were contributing to the success of the event and community, loving sports, and helping others. Emphasis of these opportunities or benefits may help in volunteer recruitment. Although these concepts or benefits tend to be intangible and beyond the reach of event organizers, volunteers can be made to feel valued and respected by their staff and event organizers. Therefore, creating an atmosphere in which volunteering is valuable and satisfying may influence volunteers to engage in volunteer work again for future events (Pauline, 2011; Wang \& Yu, 2015). Furthermore, sport event organizers 
should clearly describe and indicate messages and purposes of the sport event and volunteers' contributions. If the organization highlights the extent to which volunteers support and contribute to making a sport event a success, volunteers may be more orientated to the goals of the organization by being aware of how they can contribute in meaningful ways.

Finally, understanding of differences in motives is likely to produce a unique profile of each subgroup to help allocate the tasks to suitable volunteers for better engagement. For example, volunteers who were mostly motivated by love of sport and community involvement (cluster 2 in this study) were mainly males who were retired from the workforce. They were normally experienced volunteers and willing to volunteer, spending a relatively large amount of time doing so before and during the event. This group may like to do volunteer work related to supporting sport players or offering a certain sport service for their community. In contrast, younger volunteers who did not have a job might like to build career-relevant interaction and networking (cluster 4 in this study). Although younger volunteers having no jobs were comparatively new volunteers in these events, they tended to be motivated by the possibility of developing a relationship with staff and managers and being closely involved in volunteering activities to prepare the sport event before it commenced. If they regarded different desires and positions as a unique profile of each group, event organizers would be better able to describe the category of volunteer they preferred. Such practical implications can make it possible for the organizers and managers to develop more effective plans to recruit and manage sport event volunteers.

\section{Research limitations and future research directions}

There were several limitations to the present study. First, this research could not collect data from all 668 volunteers, which may have some implications for non-response bias. Though it may be beneficial to identify initial profiles of volunteers with regard to sport events, findings are not generalized to the entire sport event volunteer population. Although this study collected data across a range of non-mega sport events rather than a single mega-event and was repeated 
across three different sport events, the research was limited to a specific geographical area. This limitation might result from a tendency of researchers to investigate events that are located close to where they study rather than events that are staged in other countries or regions (Kim \& Cuskelly, 2017). Due to constraints of time and financial cost, researchers are more likely to prefer the convenience and minimal cost of easy access to organizers and volunteers. Future research can repeat this methodology and assess the results at various sport events in other countries and regions, which will enhance the validity and reliability of sport event volunteer segmentation studies. Increasing the generalizability and validity of studies will attract a growing research attention in other research fields to examine various research topics alongside other sectors. In this regard, overlapping sport and tourism fields to explore the emergence of the unique potential of volunteer tourism research could be worthwhile research contribution.

Second, one of the drawbacks of applying this type research into motivation in the context of non-mega events is that smaller sample sizes are inevitable given that fewer volunteers are involved. In particular, Cluster 1 (material benefits seekers) and Cluster 4 (career and social relationship seekers) accounted for comparatively few volunteers. This is either a result of these groups actually being smaller in the volunteer population or volunteers who were motivated in this way being less likely to participate in the research. This eventually influenced on the size of the identified volunteer motivation clusters. The most efficient design occurs when cluster sizes are all equal. If cluster sizes are imbalanced, estimates from the smaller clusters will be less accurate (Donner, Birkett, \& Buck, 1981; Eldridge, Ashby, \& Kerry, 2006). However, cluster sizes often vary. According to a review by Eldridge et al. (2006), in practice, several studies inevitably reported unequal sized clusters and investigators had to consider the possible impact of variable cluster size. Given the uncertain nature of sample size calculations, it does not seem necessary to adjust sample size to achieve equal cluster sizes prior to analyses. Further, the importance of small cluster sizes in an efficient design should not be overlooked (Eldridge et al. (2006). Marshall (1996, p. 522) argued that "the optimum sample size depends upon the parameters of the phenomenon under study". As this study attempted to investigate small or 
medium sized types of sport events that are more appropriate to bringing positive effects to local host communities compared to global mega sport events (Taks, 2013), the small sized samples collected from three different types of sport events were chosen for this study. As unequal sized clusters can occur, in order to reduce at least the effects of a small sample size and increase the power of the study efforts to obtain high response rates may be needed. Researchers can chose to send reminder emails to non-respondents or provide incentives to respondents in the form of prizes by a lottery (Nulty, 2008). Alternatively, the extension of the survey period can be drive higher response rates (Nulty, 2008). Further, Ward's method of hierarchical clustering might be selected due to its tendency to generate clusters of similar size (Fredline, 2012; Mooi \& Sarstedt, 2011). Despite the use of Ward's method the clusters in this study were of unequal size.

Third, consideration of other possible motivation items will be required as motives for participating in activities could be variously formed by people's different attitudes, views, values and character. Future research might consider examining the potential motivation factors in order to explore more sustained impacts on volunteering at certain target groups.

\section{Conclusion}

This study is valuable for volunteer management in sport events and reflects a growing interest regarding volunteers within tourism settings. Volunteers are an important human resource and essential to hosting many successful sport events. Tourists who are willing to volunteer with the intention of travelling can be regarded as potential volunteers for sport events. Such volunteers tend to be a diverse group and have different motivations. Sport event organizers therefore need to pay more attention to motive profiles of different groups to better understand the characteristics of event volunteers with a view to maintain a good relationship with volunteers and develop the effective volunteer management strategies. By segmenting volunteers based on their motivations, this study identified meaningful groups of volunteers and has contributed to practical and theoretical implications for both industry and other researchers. Cognizant of the 
limitations of this current study, the results emphasize the need for further research on cluster analysis in regard to motivation. 


\section{References}

Alexander, A., Kim, S. B., \& Kim, D. Y. (2015). Segmenting volunteers by motivation in the 2012 London Olympic Games. Tourism Management, 47(2015), 1-10.

Bang, H., Alexandris, K., \& Ross, S. D. (2008). Validation of the revised volunteer motivations scale for international sporting events (VMS-ISE) at the Athens 2004 Olympic Games. Event Management, 12(3-4), 119-131. doi: 10.3727/152599509789659759

Bang, H., \& Ross, S. D. (2009). Volunteer motivation and satisfaction. Journal of Venue and Event Management, 1(1), 61-77. Retrieved from http://www.sc.edu/study/colleges_schools/hrsm/research/research_journals_and_public ations/jvem_pdfs/vol1_no1/volunteer_motivation.pdf

Bang, H., Won, D., \& Kim, Y. (2009). Motivations, commitment, and intentions to continue volunteering for sporting events. Event Management, 13(2), 69-81. doi: $10.3727 / 152599509789686317$

Barbieri, C., Santos, C., \& Katsube, Y. (2012). Volunteer tourism: on-the-ground observations from Rwanda. Tourism Management, 33(3), 509-516.

Benson, A., \& Henderson, S. (2011). A strategic analysis of volunteer tourism organisations. Service Industries Journal, 31(3), 405-424.

Cabieses, B., Tunstall, H., \& Pickett, K. (2015). Understanding the Socioeconomic Status of International Immigrants in Chile Through Hierarchical Cluster Analysis: a PopulationBased Study. International Migration, 53(2), 303-320.

Cha, S., McCleary, K. W., \& Uysal, M. (1995). Travel motivations of Japanese overseas travelers: A factor-cluster segmentation approach. Journal of travel research, 34(1), 3339.

Chelladurai, P. (2006). Human resource management in sport and recreation. Champaign, Ill: Human Kinetics.

Clary, E. G., Snyder, M., Ridge, R. D., Copeland, J., Stukas, A. A., Haugen, J., \& Miene, P. (1998). Understanding and assessing the motivations of volunteers: a functional 
approach. Journal of personality and social psychology, 74(6), 1516-1530.

doi:10.1037/0022-3514.74.6.1516

Cunningham, G. B. (2013). Theory and theory development in sport management. Sport management review, 16(1), 1-4.

Dickson, T. J., Benson, A. M., Blackman, D. A., \& Terwiel, F. A. (2013). It's all about the games! 2010 Vancouver Olympic and Paralympic winter games volunteers. Event Management, 17(1), 77-92. doi: 10.3727/152599513X13623342048220

Dickson, T. J., Benson, A. M., \& Terwiel, F. A. (2014). Mega-event volunteers, similar or different? Vancouver 2010 vs London 2012. International Journal of Event and Festival Management, 5(2), 164-179. doi: http://dx.doi.org/10.1108/IJEFM-07-20130019

Dickson, T. J., Darcy, S., Edwards, D., \& Terwiel, F. A. (2015). Sport mega-event volunteers' motivations and postevent intention to volunteer: The Sydney World Masters Games, 2009. Event Management, 19(2), 227-245.

Dolnicar, S., \& Grün, B. (2008). Challenging "factor-cluster segmentation". Journal of Travel Research, 47(1), 63-71.

Donner, A., Birkett, N., \& Buck, C. (1981). Randomization by cluster: sample size requirements and analysis. American Journal of Epidemiology, 114(6), 906-914.

Eldridge, S. M., Ashby, D., \& Kerry, S. (2006). Sample size for cluster randomized trials: effect of coefficient of variation of cluster size and analysis method. International journal of epidemiology, 35(5), 1292-1300.

Elliott, D. (2008). Voluntourism. Conde Nast Traveler. Retrieved from http://www.concierge.com/cntraveler/articles/12200

Fabrigar, L. R., Wegener, D. T., MacCallum, R. C., \& Strahan, E. J. (1999). Evaluating the use of exploratory factor analysis in psychological research. Psychological methods, 4(3), 272-299. 
Farrell, J. M., Johnston, M. E., \& Twynam, G. D. (1998). Volunteer motivation, satisfaction, and management at an elite sporting competition. Journal of Sport Management, 12(4), 288-300.

Fredline, L. (2012). Cluster analysis. In L. Dwyer, A. Gill, \& N. Seetaram (Eds.), Handbook of Research Methods in Tourism: Quantitative and Qualitative Approaches (pp.212-226). Cheltenham: Edward Elgar.

Giannoulakis, C., Wang, C. H., \& Gray, D. (2007). Measuring volunteer motivation in megasporting events. Event Management, 11(4), 191-200. doi:

$10.3727 / 152599508785899884$

Guttentag, D. A. (2009). The possible negative impacts of volunteer tourism. International Journal of Tourism Research, 11(6), 537-551.

Hair, J. F., Anderson, R. E., Tatham, R. L., \& Black, W. C. (1998). Multivariate data analysis $5^{\text {th }} E d$. New Jersey: Printice-Hall.

Hallmann, K., \& Harms, G. (2012). Determinants of volunteer motivation and their impact on future voluntary engagement: A comparison of volunteer's motivation at sport events in equestrian and handball. International Journal of Event and Festival Management, 3(3), 272-291. doi: 10.1108/17582951211262701

Hodgkinson, V. A. (2003). Volunteering in global perspective. In P. Dekker \& L. Halman (Eds.), The values of volunteering: Cross-Culture Perspectives (pp. 35-53). Springer Us. International Labor Organization. (2011). Manual on the measurement of volunteer work. Geneva: International Labor Office.

Jenkins, R. (1996). Social identity. London: Routledge.

Johnson, S. C. (1967). Hierarchical clustering schemes. Psychometrika, 32(3), 241-254.

Khoo, S., \& Engelhorn, R. (2007). Volunteer motivations for the Malaysian Paralympiad. Tourism and Hospitality Planning \& Development, 4(3), 159-167.

Khoo, S., \& Engelhorn, R. (2011). Volunteer motivations at a national Special Olympics event. Adapted physical activity quarterly, 28(1), 27-39. Retrieved from 
http://journals.humankinetics.com/AcuCustom/Sitename/Documents/DocumentItem/03 _Khoo_J3563_27-39.pdf

Kim, E., \& Cuskelly, G. (2017). A systematic quantitative review of volunteer management in events. Event Management, 21(1), 83-100.

Knoke, D., \& Prensky, D. (1984). What relevance do organization theories have for voluntary associations?. Social Science Quarterly, 65(1), 3-20.

Laverie, D. A., \& Arnett, D. B. (2000). Factors affecting fan attendance: The influence of identity salience and satisfaction. Journal of Leisure Research, 32(2), 225-246.

MacClancy, J. (1996). Sport, identity and ethnicity. In J. MacClancy (Ed.), Sport, identity and ethnicity (pp. 1-20). Oxford: Berg.

Marshall, M. N. (1996). Sampling for qualitative research. Family practice, 13(6), 522-526.

Monga, M. (2006). Measuring motivation to volunteer for special events. Event Management, 10(1), 47-61.

Mooi, E. A., \& Sarstedt, M. (2011). A concise guide to market research: the process, data, and methods using IBM SPSS Statistics. Heilderberg (DE): Springer.

Nulty, D. D. (2008). The adequacy of response rates to online and paper surveys: what can be done?. Assessment \& evaluation in higher education, 33(3), 301-314.

Pauline, G. (2011). Volunteer satisfaction and intent to remain: an analysis of contributing factors among professional golf event volunteers. International Journal of Event Management Research, 6(1) 10-32.

Schlesinger, T., \& Gubler, R. (2016). Motivational profiles of sporting event volunteers. Sport in Society, 19 (10), 1-21.

Sharififar, F., Ganjouie, F. A., Tondnevis, F., \& Zarei, A. (2011). Effect of Social Factors and Motives on Commitment of Sport Events Volunteers. TECHNICS TECHNOLOGIES EDUCATION MANAGEMENT-TTEM, 6(1), 184-190.

Sheppard, A. G. (1997). The sequence of factor analysis and cluster analysis: Differences in segmentation and dimensionality through the use of raw and factor scores. Tourism Analysis, 1, 49-58. 
Shoemaker, S. (1994). Segmenting the US travel market according to benefits realized. Journal of Travel Research, 32(3), 8-21.

Strigas, A. D., \& Jackson Jr, E. N. (2003). Motivating volunteers to serve and succeed: Design and results of a pilot study that explores demographics and motivational factors in sport volunteerism. International Sports Journal, 7(1), 111-123.

Sutton, R. I., \& Staw, B. M. (1995). What theory is not. Administrative Science Quarterly, 40, $371-384$.

Taks, M. (2013). Social sustainability of non-mega sport events in a global world. European Journal for Sport and Society, 10(2), 121-141.

Taylor, T., Darcy, S., Hoye, R., \& Cuskelly, G. (2006). Using psychological contract theory to explore issues in effective volunteer management. European Sport Management Quarterly, 6(2), 123-147.

Tourism Research \& Marketing. (2008). Volunteer tourism: A global analysis. Barcelona, Spain: Association for Tourism and Leisure Education.

Tribe, J. (2008). Tourism: a critical business. Journal of Travel Research, 46 (3), 245-255.

Trninić, V., Jelaska, I., \& Štalec, J. (2013). Appropriateness and limitations of factor analysis methods utilized in psychology and kinesiology: Part II. Fizička kultura, 67(1), 1-17.

Twynam, G. D., Farrell, J. M., \& Johnston, M. E. (2002). Leisure and volunteer motivation at a special sporting event. Leisure/Loisir, 27(3-4), 363-377. doi: $10.1080 / 14927713.2002 .9651310$

VanSickle, J. L., Pierce, D. A., \& Diacin, M. (2015). Volunteer motivations at the 2012 Super Bowl. International Journal of Event and Festival Management, 6(3), 166-181. doi: http://dx.doi.org/10.1108/IJEFM-12-2014-0029

Visalakshi, N. K., \& Thangavel, K. (2009). Impact of normalization in distributed k-means clustering. International Journal of Soft Computing, 4(4), 168-172.

Wang, C., \& Yu, L. (2015). Managing student volunteers for mega events: motivation and psychological contract as predictors of sustained volunteerism. Asia Pacific Journal of Tourism Research, 20(3), 338-357. 